with stock on the crop, there is an added component to soil loss risk depending on grazing management and stock type.

A consistent response across all themes was the necessity to "Make sure you do it properly to make sure you get a good crop", "you can't cut corners".

It was clear from the interviews that the detail of successfully establishing crops devolved to the farm level based on the quality of decisions such as fertiliser requirements in relation to soil nutrient levels and crop requirements, and potential for weed and pest impacts. The choice of crop was determined by the type and/ or class of animal for which it was targeted, with the area determined by both availability and crop volume to sustain or grow animals. Differences in the pattern of seasonal rainfall dictated when to establish a helicrop, and were based on soil moisture rather than a calendar event. Delaying a decision until soil temperatures were suitable was clearly outweighed by considerations of soil moisture and ensuring the crop was established well before the soils dried out.

The preceding dialogs record the experiences of the four interviewees at a time when all have come through the initial learning experiences for helicropping. Attention needs to be paid to their experiences and what might be done in the future if other hill country farmers are to take up the practice of helicropping with confidence.

\section{Conclusions}

All four respondents reported profitable returns from their experiences with helicropping. Combined with their experiences of reliable crop establishment this has convinced these early adopters that the practice was a good fit within their farming practices and did not conflict with their obligations as environmenta custodians looking to preserve hill country soils. Their che experiences fit well with the Pastoral Industry Forage nt and on-farm innovation (Forage Strategy 2016).

\section{ACKNOWLEDGEMENTS}

The authors acknowledge the generous input from Colin Armer, Paul Bodle, Geoff Fitzgerald and Mark Grace in sharing their experiences while using helicropping that are recorded in this paper.

\section{REFERENCES}

Douglas, G.B.; Tozer, K.N.; Cameron, C.A.; Fraser, T.J.; Muir, P.D.; Moss, R.A.; Rennie, G.M.; Knight, T.L. 2013. Successful establishment of oversown chicory and plantain on uncultivable hill country. Proceedings of the $22^{\text {nd }}$ International Grassland Congress: 523-524.

Galetta, A. 2013. Mastering the semi-structured interview and beyond: from research design to analysis and publication. New York University Press.

Gillespie, B.J.; Lucas, R.J.; Moot, D.J.; Edwards G.R. 2006. Can topdressing with salt increase oversowing success and pasture quality on steep, south facing slopes in hill country pastures? Proceedings of New Zealand Grassland Association 68: 349-353.

Lane, P.M.S.; Willoughby, B.E. 2016. Hill country cropping with no land-based equipment. Grassland Research and Practice Series 16: 251-256.

Lambert, M.G.; Rhodes, A.P.; Barker, D.J.; Bircham, J.S. 1985. Establishing and managing improved plants in hill country. Grassland Research and Practice Series 3: 31-34.

Macfarlane, M.J.; Bonish, P.M. 1986. Oversowing white clover into cleared and unimproved North Island hill country. The role of management, fertiliser, inoculation, pelleting and resident rhizobia. Proceedings of New Zealand Grassland Association 47: 43-51

Pastoral Industry Forage Strategy. 2016-2036. https// www.nzgajournal.org.nz/index.php/JoNZG/about/ contact

Tozer, K.N.; Moss, R.A.; Cameron, C.A.; Rennie, G.M.; Douglas, G.B. 2016. Litter can enhance pasture establishment on non-cultivable hill country. Grassland Research and Practice Series 16: 243250.

Tozer, K.N.; Douglas, G.B. 2016. Pasture establishment on non-cultivable hill country: a review of the New Zealand literature. Grassland Research and Practice Series 16: 213-224.

\title{
Information required from research programmes when introducing legume forage systems into challenging environments
}

T.A. NELSON ${ }^{1}$, S.M. ZYDENBOS ${ }^{2}$ and D.R. STEVENS ${ }^{3}$ ${ }^{1}$ AgResearch, Ruakura Research Centre, Private Bag 3123, Hamilton 3240, New Zealand ${ }^{2}$ AgResearch, Lincoln Research Centre, Private Bag 4749, Christchurch 8140, New Zealand ${ }^{3}$ AgResearch, Invermay Research Centre, Private Bag 50034, Mosgiel, New Zealand

tracy.nelson@agresearch.co.nz

Abstract

The use of legumes to increase animal performance is well known, but why are sheep and beef farmers not using a legume forage system in New Zealand hill country, and what information do they need before introducing a legume forage system? A co-innovation process was started to explore the challenges sheep and beef farmers face introducing a legume forage system into hill country and their information needs. The first step in this process, reported here, was to run eight workshops throughout New Zealand which 105 farmers and agribusiness representatives attended. Results showed that getting the right information from trusted sources was the highest priority for farmers looking to introduce a legume forage system. Information provided by the science community and industry needs to be region specific as the range of knowledge around legume species differs across regions. Some of the information required by farmers is already well documented, but may not be in the hands of the right people.

Keywords: challenges, forage, farm system, information requirements, knowledge, legumes, sheep and beef farmers

\section{Introduction}

Evidence is emerging that pasture production in New Zealand hill country has declined in the past 10 to 15 years (Mackay \& Costall 2016), especially on some slopes and aspects. So while maintaining advances in productivity and profitability by utilising more of the feed grown (Fennessey et al. 2016), this option is rapidly running out. New technologies are required to maintain productivity and profitability into the future. Hill country development and sustainability are hampered by limitations of soil nitrogen and water. Legumes, by fixing atmosheic $\mathrm{N}$, incense water use effien, fixing atmospheric $\mathrm{N}$ and supply high quality feed to ewes and lambs and cows and calves, providing stock for red meat supply at premium times. Previous science developing forage legumes has often failed as farming practices have not changed to capture the benefits of feed quality, improved water use efficiency and feed quantity, that are proven to increase animal production (Stevens et al. 2012).
The use of legumes to increase animal performance is well known (Lambert \& Litherland 2000), however, sheep and beef farmers are not adopting legume forage systems in New Zealand hill country. What information do they need before introducing such a system? This research reported aimed to understand the perceived challenges farmers face when introducing a legume forage system and what information requirements lopt wuch a system. This paper reports e to make a change to their farm system. Such information will help researchers incorporate these needs into research programmes.

\section{Methods}

For complex issues, such as changing a farm system, a co-innovation approach can assist with change (Turne et al. 2014). This approach involves a number of people and organisations working together in the design and implementation of research. A co-innovation process was used to explore the challenges and information requirements when introducing a legume forage system into hill country. A benefit of 'co-innovation' is better understanding of the problems as a result of involving more people and organisations, which in turn provides reater confidence that the solutions will be successful ( through a process of interaction and social learning, become aware of the values and needs of participants in the co-innovation system. Ideally, this enhances each person's moral and knowledge perspectives and increases their respect and opportunity for developing a solution that attempts to satisfy the needs of all (Hounkonnou et al. 2012; Klerkx et al. 2012; Klerkx \& Nettle 2013). The hypothesis was, if people and organisations from all parts of the system are involved in specifying the problem and co-developing a solution, then that solution is more likely to be fit-for-purpose and be adopted by the end-users (who helped develop it) than would otherwise be the case.

Workshops

Eight farmer workshops were held throughout New 
Zealand to provide understanding of what challenges to legume use are present in different environments. The location of the workshops were based on eight distinc geo-climatic regions, five in the North Island and three in the South Island. An open invitation was sent to local sheep and beef farmers through the Beef + Lamb New Zealand network. In total, 105 self-selected participants attended the workshops. All workshops had a farm researcher ensuring the information was obtained in a consistent manner enabling direct comparisons of data between workshops. Some agri-business personne attended some of the workshops, but the numbers were not large enough to provide a consistent view of agribusiness needs.

The workshops focused on 5 key topics: (1) current legume system, (2) key challenges, when using (3) inform of chang to a is he value legunes would need to add to the system. The workshop was not designed to change farmer minds on legumes, but rather for the researchers to hea the information requirements needed before farmers introduced a legume forage system.

Before tailoring information requirements for farmers it is essential to understand the perceived challenges that face farmers when implementing a legume forage system. The workshop structure required participants to reflect on their experience and document perceived challenges independent of other participants. Participants were then asked to categorise their challenge(s) by placing it at one of seven stations around the room. These stations were titled: Biophysical, Whole farm systems, Practical, Technical, Social, Environmental and Financial. The data for each challenge were then pooled across the eight works chops to identify major concerns. An open group discussion identified information requirements and delivery methods at each workshop.

\section{Results}

Challenges facing farmers when implementing legume forage systems were first identified. Challenges were categorised in one of seven categories (outlined above) A pooled set of challenges were developed to enable a broad representation of the frequency of occurrence of the challenges identified (Figure 1).

Information requirements were the greatest challenge identified. This included getting the right information at the right time, and making sure that their wide rural support networks, including seed companies an fertiliser representatives, have the right information. The second greatest challenge was the question of economics (costs, returns and investment questions have been pooled).

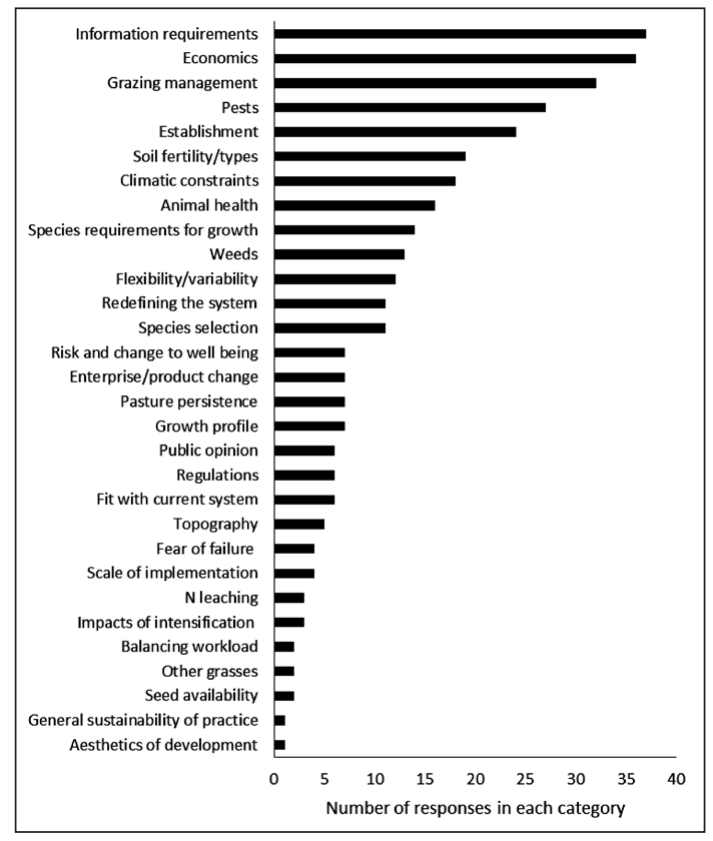

Figure 1 Challenges that face farmers when implementing legume forage systems.

Grazing management was of greatest importance in the practical management realm, although weeds and pests and establishment were also highly represented. Other areas that were considered important included the base resources of soils and climate, particularly the response to variability in the weather

The question on how to tailor information was explored in an open discussion session. Results (Table 1) indicated that there were three main layers to the way farmers viewed information. The first was the type of information that was required. This weflected the challenges that were identified and that providing information would alleviate or solve the problem. However, much of the discussion about information was not about the lack of information, but rather how the information needed to be delivered and who should be involved. Farmers wanted to know what legumes work for which farm system, followed by on-farm field days and workshops.

The role of rural professionals and agribusiness personnel was identified as key to ensuring that messages were consistent and of a high quality, enabling farmers to make appropriate decisions. The concept of ensuring that information was tailored to local farming systems and conditions was recognised as an important role for local agribusiness and rural profession groups. Training to ensure that local professionals understood the technology and practices associated with legume forage systems was highlighted as a need.

\section{Discussion}

The complexity of changing to a legume forage system has limited the impact of previous research. Investigations of end-users needs and the information they require, will inform the design of future extension programmes and help define rates of adoption of complex technologies. Changing to a legume forage system has major consequences many of which add value to the farming system and farming system and individual, while some

The complexity that came out of the workshops was that many of the biophysical factors like grazing management, weeds, pasture management and pests are all inter-related, as were the economics and flexibility of the farming enterprise. So while each of the issues can be defined in isolation it is only when they are combined that a legume forage system can be designed. It is important to realise that while the id of challenges provides some insight into information needs, the relative representation may not necessarily represent their real importance. The greater the number of representations of a category, the more likely they were to be represented in different regions. The occurrence of some of the challenges, e.g. animal health and species selection, may represent the lack of familiarity of the group with legume forage systems. However, some others, such as weeds and pests, reflect direct experience with these challenges that were yet to be resolved. Regulations and public opinion were noted infrequently, but if regulation prevents practice then meeting other requirements such as grazing management, will not change the outcome.

While some challenges were specific to some regions, most were evident in all regions. The challenges also demonstrated overlap between the initial categories. Information provided by the science community and industry needs to be region specific as the range and depth of knowledge around legume species is different across regions. The types of issues and the way farmers view the use of legumes also varied across the region. Information requirements were the greatest

Table 1 Information requirements for farmers implementing legume forage system

\begin{tabular}{ccc}
\hline Type of information & Delivery requirements & Who needs to be involved \\
\hline Management guidelines & Supportive network & Farmers \\
Animal nutrition & Training of rural professionals & Agribusiness \\
Weed and pest control & Demonstration & Science \\
Animal health & Consistent messages & Trainers \\
Farm systems design & Local examples & Industry support \\
Environmental impacts & Appropriate language & \\
Economics & Field days & \\
& Workshops & \\
\hline
\end{tabular}

recognised challenge. This included current knowledge hat is not available at the local level, but also further knowledge that may be required across the range of categories. There are two parts to information requirements. The first is what information is known and can be provided immediately to farmers and their agribusiness support systems? The second is what information is unknown, which defines the science needs? The current knowledge needs to be identified and developed into approprinte packages for both fur and veterinarians need to be engaged in the process to

Some of the information, like requirements for clover stablishment, are already well documented, but may not be in the hands of the right people. In regions where oversowing is not regularly practised, there is a need for more people and some training, to make sure that best practices are implemented.

A lack of or a need to acquire more knowledge was the highest rated social risk. This recognises the need to understand new management systems when mplementing legume forage systems. The risk of some farmers attempting to implement legume forage systems without changing current thinking was also strongly recognised. More labour also means more people management skills are needed so staff can also understand how to operate a legume forage system. implementing a legume forage system is only the first step in tailoring information packages. Farmers need information before they need to implement a decision Information needs to be provided in a way which armers understand. Suggestions included practical on-farm demonstrations in a climate that was similar to their farming system, and information presented that getting the right information from trusted sources
was their highest priority. Providing farmers with was their highest priority. Providing farmers with
rural support networks, such as seed and fertiliser co-develop material and delivery programmes.

Understanding the challenges farmers face when in a clear, simple way. Workshops participants noted 
representatives, armed with correct and relevant information was identified as vital. Some of the information required to address the noted challenges is already well documented, but needs to be transferred to the relevant farmer networks.

\section{ACKNOWLEDGEMENTS}

Many thanks to all the farmers and agribusiness people who gave their time freely to help with the coinnovation approach to designing new legume forage systems for hill country farming. This research was funded by the Pastoral 21 programme, a collaborative venture between DairyNZ, Fonterra, Dairy Companie Association of New Zealand, Beef + Lamb New Zealand and the Ministry of Business, Innovation and Employment.

\section{REFERENCES}

Fennessey, P.F.; Glennie, S.F.; McCorkindale, A.B 2016. Innovations behind the farm gate that will influence performance of hill farming. Grassland Research and Practice Series 16: 15-20.

Hounkonnou, D.; Kossou, D.; Kuyper, T.W.; Leeuwis, C.; Nederlof, E.S.; Röling, N.; Sakyi-Dawson, O.; Traoréj, M.; van Huis, A. 2012. An innovation systems approach to institutional change: smallholder development in West Africa. Agricultural System 108: 74-83.

Klerkx, L.; Nettle, R. 2013. Achievements and challenges of innovation co-production support initiatives in the Australian and Dutch dairy sectors: A comparative study. Food Policy 40: 74-89.

Klerkx, L.; van Mierlo, B.; Leeuwis, C. 2012. Evolution of systems approaches to agricultural innovation: concepts, analysis and interventions. pp. 457-483. In: Farming systems research into the 21st century: the new dynamic. Eds. Darnhofer, I.; Gibbon, D.; Dedieu, B. Springer, Netherlands.

Lambert, M.G.; Litherland, A.J. 2000. A practitioner's guide to pasture quality. Proceedings of the New Zealand Grassland Association 62: 111-115.

Mackay, A.D.; Costall, D.A. 2016. Long-term changes in soil fertility in hill country. Grassland Research and Practice Series 16: 157-162.

Rijswijk, K.; Small, B.; Rhodes, H.; Turner, J.; Peoples, S.; Horita, A.; Beechener, S. 2015. Heifer rearing and Canterbury nutrient me S. 2015. Heifer rearing project progress report. AgResearch, Ruakura.

Stevens, D.R.; Thompson, B.R; Carruthers, A.; Wall A.J.; Casey, M.J.; Phiskie, R.; Young, R.; Moot, D.J. 2012. Understanding the role of spring grazing of lucerne in the Central Otago environment. Proceedings of the New Zealand Grassland Association 74: 69-75.

Turner, J.; Stevens, D.; Rijswijk, K. 2014. Revitalising the role of rural professionals in primary sector innovation Primary Industry Managenert 24.

\section{Implications of increased use of brought-in feeds on potential environmental effects of dairy farms in Waikato}

S.F. LEDGARD ${ }^{1}$, N.L. BARTLETT ${ }^{1}$, P.J. VAN BOHEEMEN ${ }^{2}$, B.R. WILTON S.B. ALLEN ${ }^{2}$ and D.P. MUGGERIDGE

I AgResearch Ruakura, Private Bag 3123, Hamilton 3240, New Zealand ${ }^{2}$ The Tatua Co-operative Dairy Company Limited, Private Bag 800, Morrinsville 3340, New Zealand stewart.ledgard@agresearch.co.nz

\section{Abstract}

The effects of increased use of brought-in feeds were evaluated across 25 dairy farms in central Waikato. Farms were classified into low, medium and high feedinput categories based on $<500,500-1200$ and $>1200$ $\mathrm{kg} \mathrm{DM} / \mathrm{cow}$, covering a range typical of that in the main dairying regions of New Zealand. Average milksolids (MS)/ha was 1087 and $1900 \mathrm{~kg}$ in the low and high feed-input categories, but total land-use/tonne MS was the same when all off-farm land was accounted for. Average estimated on-farm nitrogen $(\mathrm{N})$ leaching increased from 26 to $30 \mathrm{~kg} \mathrm{~N} / \mathrm{ha} /$ year between the low and high feed-input categories, but off-farm leaching sources were equivalent to an increase of 20 and $84 \%$, respectively. Greenhouse gas emissions/on-farm hectare were $61 \%$ higher on high feed-input farms, but the carbon footprint and $\mathrm{N}$ leaching per tonne MS were similar across feed-inpt categoies. High feed-ine finilar acoss feed-input cact farms used feed-pads and increased effuent area (66 versus $21 \%$ of farm) to increase nutrient efficiency.
Mitigation analyses indicated that $\mathrm{N}$ leaching could be decreased by optimising effluent area, reducing $\mathrm{N}$ fertiliser rate and utilising low-N feeds.

Keywords: nitrogen leaching, whole farm system, greenhouse gases, land use

\section{Introduction}

Dairy farming in New Zealand has intensified in recent decades, with increased milk production per hectare associated with the use of nitrogen $(\mathrm{N})$ fertiliser, irrigation and increased use of brought-in feeds. For example, the average use of dry matter (DM) in brought-in feed on NZ dairy farms was $970 \mathrm{~kg} \mathrm{DM} /$ ha in 2004/2005 and $2550 \mathrm{~kg}$ DM/ha in 2014/2015 (source: ProfitWatch and DairyBase from DairyNZ).

The increased feed intake will be associated with increased nutrient intake and excretion by animals, which potentially could lead to greater losses of $\mathrm{N}$ and phosphorus $(\mathrm{P})$ to waterways. However, various management practices that affect nutrient losses, such as farm dairy effluent (FDE) management, have improved over time (e.g. PCE 2012). Farmlet research trials in Waikato have shown large increases in $\mathrm{N}$ losses with ncreased use of $\mathrm{N}$ fertiliser, relatively small changes on armlets (milking platform only) with brought-in maize silage and large potential reduction in $\mathrm{N}$ leaching with farm management and mitigations (e.g. Ledgard et al. 2006; Shepherd et al. 2017).

The aim of this study was to evaluate productivity, nutrient losses and wider environmental indicators at on-farm and whole system levels for 25 case study dairy farms in central Waikato with varying levels of use of brought-in feeds.

\section{Methods}

Twenty-five case study dairy farms from the Tatuanu area of central Waikato were selected and classified into low, medium and high feed-input levels based on brought-in feed of $<500,500-1200$ and $>1200 \mathrm{~kg}$ $\mathrm{DM} /$ cow/year. Farm numbers in each category were 6, 11 and 8, respectively. Farm records were collected for 2014/2015 and cross-checked with farmers. Thus, it uses real farm data but the wider representativeness for New Zealand in relation to level of brought-in feeds is uncertain.

Data from farms were modelled using the OVERSEER ${ }^{\circledR}$ nutrient budget model version 6.2.3 (hereafter called OVERSEER; Wheeler et al. 2003) to estimate $\mathrm{N}$ and $\mathrm{P}$ losses, and a life cycle assessment (LCA) model that complied with International Dairy Federation (IDF 2015) guidelines to estimate total greenhouse gas (GHG) emissions. The LCA accounted for all emissions from production, transportation and use of inputs from production, transportation and use of inputs including fertilisers and feeds. Modelling accounted for the dairy farm (milking platform), as well as land use for rearing replacements off-farm (based on the MP for the brought-in feed. For the latter, average published data on crop yields and inputs (e. Ledgard \& Falconer 2015) were used with assiated N leaching calcula for crop systems using OVERSEER or from published data (Schmidt 2007). Excretion of $\mathrm{N}$ by animals wa calculated in OVERSEER from the difference between $\mathrm{N}$ intake and $\mathrm{N}$ output in products. The FDE componen of this calculated in OVERSEER was based on the relative time cows spent in the farm dairy, yards and feed-pad areas. The remaining excreta-N was deposited 